\title{
A INFLUÊNCIA DO DISTANCIAMENTO SOCIAL CAUSADO PELA PANDEMIA DE COVID-19 NA VIOLÊNCIA CONTRA MULHER
}

\section{Mylena Lima'; Neemias Fernandes²; Francielle Agne Tybusch ${ }^{3}$}

${ }_{1}^{1}$ Acadêmica Mylena Lima; limadasilvamylena@gmail.com

${ }^{2}$ Acadêmico Neemias Fernandes; neemiasbianchin@gmail.com

3 Orientadora Francielle Agne; francielleagne@gmail.com

\section{RESUMO}

O presente trabalho tem 0 intuito de analisar a efetividade dos direitos e garantias fundamentais das mulheres em meio ao isolamento social causado pela pandemia, buscando analisar, por meio de uma abordagem dedutiva, os dados de ameaça, lesão corporal, estupro, feminício consumado e feminicídio tentado, fazendo assim, um brevê comparativo histórico de crimes contra a mulher que ocorreram do inicio do combate a Covid-19 e os tempos atuais.

Palavras-chave: Mulher; Pandemia; Violência.

Eixo Temático: Direitos, Políticas Públicas e Diversidade

\section{INTRODUÇÃO}

Devido a pandemia da Covid-19, houve a necessidade de um isolamento social e por consequência, o que é a questão fundamental objetiva de análise do presente, a alteração nos índices de violência contra mulher, bem como, a verificação da efetividade dos meios legais do Estado na proteção das vítimas. Analisando se os direitos e garantias fundamentais das mulheres, resguardados em lei, estão de fato sendo aplicados nas políticas públicas de segurança.

Apesar de ser recente a legislação especializada na proteção contra a violência de gênero, constantemente nos deparamos na mídia com notícias de violência contra mulher e de feminicídios durante a quarentena da pandemia da Covid-19, causando indagações a respeito do tema: A lei Maria da Penha e as medidas adotadas pelo governo do RS são eficazes para combater os números de dano físico, patrimonial, sexual, moral e psicológico cometidos contra mulher? 


\subsection{BREVE CONTEXTO HISTORICO DOS DIREITOS E GARANTIAS FUNDAMENTAIS DAS MULHERES}

A desigualdade de gênero deu início aos movimentos de reivindicações das mulheres por direitos, com o movimento sufragista, no começo no século XIX, pois havia uma necessidade de assegurar a igualdade entre os sexos, assim Rosane B. M. da Rocha B. Terra. e Quelen Brondani de Aquino (2012, p. 175) colocam:

Diante dessas relações de gênero assimétricas, pode-se extrair que da instituição familiar resulta uma série de diferenças entre os papéis desempenhados por homens e mulheres na sociedade [...] não apenas no ambiente doméstico, mas evidentemente das esferas públicas da sociedade.

Tal assimetria fez com que as mulheres questionassem porque não podiam exercer determinadas funções. As sufragistas debatiam do por que eram consideradas incapazes de participar da política, onde o principal argumento dos homens era de que participar iria prejudicar na conservação das famílias. O movimento contava com pedidos formais na Assembleia Legislativa, contudo, quase sempre não eram aceitos, assim, deu-se início a União Social e Política das Mulheres. Com esses movimentos, foi aprovado o voto feminino e assim, aos poucos, as mulheres foram conquistando seus direitos.

Alguns anos depois, com a Constituição Federal a igualdade de gênero recebeu uma previsão legal, conforme caput do art. 50: "Todos são iguais perante a lei, sem distinção de qualquer natureza, garantindo-se aos brasileiro e aos estrangeiros residentes no País a inviolabilidade do direito à vida, à liberdade, À igualdade, à segurança e à propriedade" (BRASIL, 1988), assim, é importante destacar que a expressão inicial é "todos", logo, universal para as garantias previstas no artigo, porém, o direito da mulher é tratado com desigualdade de poder e com violência de gênero em nossa sociedade, em razão de vivermos uma cultura de opressão, onde os números de violência e desigualdade são alarmantes. Contudo, deve-se considerar o conceito de gênero, na perspectiva contemporânea, o qual, passou a considerar os atributos culturais diferentes para cada sexo biológico humano. Assim, tem-se o pensamento de Anna Colling (2004, p. 36), que descreve: 
O pensamento da diferença não busca a homogeneização no mesmo, mas quer manter e ver reconhecidas suas diferenças e ao mesmo tempo reconhecidos seus direitos universais e básicos. Defender a igualdade como direito universal não deve implicar que todos os indivíduos sejam iguais.

A própria Constituição Federal garante que não existe tal desigualdade, como dispõe o primeiro inciso do art. 50: "homens e mulheres são iguais em direitos e obrigações, nos termos desta Constituição" (BRASIL, 1988), ainda sim, se faz necessário discutir os chamados direitos da mulher, podendo ser considerada uma ramificação dos Direitos Humanos, que são fundamentados pelo Princípio da integridade e dignidade da pessoa humana. Da mesma maneira que a Constituição Federal, os Direitos Humanos também são ditos universalistas, contudo, as condições históricas, econômicas, sociais e de gênero fazem com que essa universalidade não saia do plano teórico, assim, embora tenhamos uma previsão legal, a sociedade ainda faz uma discrmininação contra mulheres.

Como relata a World Health Organization (1997), a violência de gênero, é um fenômeno complexo e de alta prevalência no Brasil, assim, foi reconhecida como um problema de saúde pública, dessa forma, após a Constituição Federal de 1988, houveram algumas legislações de fundamental importância tratando dos direitos das mulheres, tal qual, a Convenção de Belém de Pará, criada em 1994 e promulgada em 1996. Foi o primeiro Tratado Internacional de proteção ao direitos das mulheres, onde o conceito trazido pela Convenção Interamericana para prevenir, punir e erradicar a violência contra mulher, fez com que o houvesse um reconhecimento da violação dos direitos humanos, bem como, refere-se a uma ofensa à dignidade humana Desse modo, pode-se criar um padrão de violência contra mulher, sendo esse de morte, sofrimento físico, sexual ou psicológico, o qual, serviu posteriormente de base, para criação da Lei Maria da Penha.

Criada em 2006, a Lei Maria da Penha surgiu em decorrência de um caso de violência doméstica ocorrido em 1983. O agressor era marido da vítima, Maria da Penha Maia Fernandes, que sofreu tentativas de homicídio dentro de seu casamento por mais de vinte anos. A primeira tentativa do agressor foi feita enquanto Maria da Penha dormia, por meio de uma arma de fogo, acertando um tiro nas costas e deixando a vítima paraplégica. Posteriormente, o agressor tentou eletrocutar e afogar a vítima, assim, temendo por sua vida, Maria da Penha denunciou os abusos que estava sofrendo, 
porém, seu já ex marido só foi condenado dezenove anos depois, ficando dois anos em regime fechado. Com o ocorrido, foi realizada uma denúncia do caso à Corte Interamericana de Direitos Humanos, que impôs ao Brasil a criação de uma legislação para casos de violência doméstica.

\subsection{VIOLÊNCIA DOMÉSTICA E POLÍTICA DE SEGURANÇA: UMA ANÁLISE DOS SEUS TIPOS E CARACTERÍSTICAS}

$\mathrm{Na}$ luta por direitos, tanto os movimentos feministas, quanto as organizações, foram constituindo um campo de poder que tem sido de suma importância para fazer valer os direitos já conquistados, bem como, para abrir a possibilidade para a conquista de novos direitos. O processo de luta pelos direitos, voltando sua atenção para a discriminação, ao longo das últimas quase quatro décadas, tras um importante conjunto avanço legislativo e de políticas públicas, contribuindo assim, para ampliação de acesso à justiça (BOURDIEU, 1999).

Embora ainda seja rotineiro acreditar que a violência contra mulher trata-se apenas de violência física, de forma que a conduta do agressor, ofenda a integridade ou saúde corporal da mulher, como por exemplo, uma lesão com objeto cortante ou perfurante, deixando marcas visíveis, contudo, convém acentuar a definição de violência doméstica, prevista no art. 5ํㅡㄹ da lei 11.340/06, conhecida popularmente como Lei Maria da Penha, afirma que visa combater também a violência psicológica, sexual, patrimonial e moral: "Para os efeitos desta Lei, configura violência doméstica e familiar contra a mulher qualquer ação ou omissão baseada no gênero que lhe cause morte, lesão, sofrimento físico, sexual ou psicológico e dano moral ou patrimonial", logo, como ressalta a Secretária Nacional de Enfrentamento à Violência contra Mulheres (2011), a violência moral e o abuso psicológico e verbal fazem parte da violência de gênero.

Dessa forma, para melhor esclarecimentos, considera-se violência doméstica psicológica aquela que causa algum dano emocional, que diminua a autoestima ou então que tente controlar suas ações, suas atitudes e opiniões, feito geralmente por meio de ameaças, manipulação, chantagem ou insultos. A violência sexual, não trata- 
se apenas da participação indesejada da vítima na relação sexual, mas também do uso de coação ou força para que a mulher presencie a relação sexual, trata-se também de impedir o uso de métodos contraceptivos, tal qual, forçar o aborto ou gravidez. Já a violência patrimonial vai além de controlar o dinheiro ou deixar de pagar pensão alimentícia, pois também trata de danos propositais a objetos de valor material ou sentimental. E a violência moral é a conduta que configura calúnia, difamação ou injúria, como acusar a mulher de traição.

Embora a Lei Maria da Penha tenha sido um marco para que pudesse ser definido as formas de violência contra mulher, tal qual, as medidas protetivas, pois até 2006, não havia previsão no Código Penal brasileiro, atualmente, também temos a Lei do Feminicídio, visto que o feminicídio é corroborado em casos extremos de violência doméstica e familiar. A Lei do Feminicídio, 13.104/15, foi criada por meio de uma orientação do Conselho Parlamentar Mista de Inquérito, sobre violência contra a Mulher do Congresso Nacional, aplicando-se nos casos em que o crime é resultado de violência doméstica ou familiar, bem como, aplicada nos casos de descriminação contra a condição da mulher, isto é, quando há misoginia. A Lei prevê uma pena de reclusão de doze a trinta anos, podendo ser aumentada de $1 / 3$ (um terço), até a metade, conforme art. $1^{\circ}, \$^{\circ}$.

Nas últimas décadas, foram feitas diversos estudos sobre a violência de gênero contra as mulheres, mostrando as diferentes organizações e instituições que se empenham em revelar a magnitude das diversas formas de violência contra as mulheres (PASINATO, 2012.) Assim, em suma, ambas as leis, tratam-se de métodos para combater à violência doméstica, contudo, a Lei Maria da Penha não prevê penalidades ao agressor, mas sim, prevê medidas protetivas para evitar mortes que estão sendo sinalizadas por meio de violência doméstica, e a Lei do Feminicídio, tem uma previsão legal de pena para os casos onde mulheres são assassinadas por serem do sexo feminino. As duas leis podem coexistir em um único caso, dado que, a Lei Maria da Penha tem previsão legal para ser capaz de provar o feminicídio, podendo aumentar a penalidade do agressor, no qual, pode-se exemplificar o depoimento de uma denúncia sendo apresentado à Justiça durante o processo, num caso de feminicídio, onde uma medida protetiva poderia ter salvo a vida da vítima. 


\subsubsection{DETALHAMENTO DA POLÍTICA PÚBLICA DE SEGURANÇA}

Política pública de segurança é um conjunto condicionado à estratégia de segurança pública, sendo aplicada nos níveis de governo federal, estadual e municipal, tendo como objetivo a preservação e manutenção da ordem pública, prevenção à criminalidade e trazendo transparência e partilha das práticas realizadas pelo órgão de política pública de segurança, com essas políticas públicas devem ser integradas às demais políticas em curso.

Especialmente àquelas cujo desenvolvimento impactarão nas ações de segurança, como as de ordenamento territorial, de desenvolvimento urbano, de atendimento às pessoas com mobilidade reduzida, de atenção às pessoas com deficiências, de saúde, de meio ambiente, de infraestrutura, de educação, de ciência e tecnologia, assim como as demais políticas setoriais ligadas ao desenvolvimento sustentável, tolerância racial, de gênero e religiosa, tendo em vista a promoção de um ambiente 'sem discriminação e seguro para todos.

\subsection{A (IN)EFETIVIDADE DOS DIREITOS E GARANTIAS FUNDAMENTAIS DAS MULHERES QUE SOFREM INJUSTA AGRESSÃO EM CRISE ATÍPICA NA PREVENÇÃO CONTRA A PANDEMIA}

Para lecionar e trazer maior clareza a respeito do tema, o presente trabalho limitouse a utilizar dados de crimes contra a mulher que foram ocorridos no período da pandemia, substanciados através de mídia digital, impressa e principalmente pela coleta de indicadores disponíveis ao público através do site da Secretaria de Segurança Pública do Estado do RS. Após análise dos dados oficiais expostos, uma considerável variação em todos os indicadores de violência no Estado do RS, sendo considerado os meses de Janeiro até Julho dos anos de 2019 a 2021.

Os crimes de feminicídio no decorrente ano de 2019 antes da pandemia e isolamento social para combate a Covid-19 de Janeiro até Julho tiveram contabilizados "55 casos de consumação de feminicídio" (SIP/PROCERGS,2019), mas tendo-se uma variação 
nesses números nos anos de 2020 e 2021, com a implementação do isolamento social por conta da pandemia, utilizando-se dos dados de mês citado anteriormente, foi contabilizados no ano de 2020, "53 casos de feminicídio e um aumento de 58 casos no ano seguinte" (SIP/PROCERGS, 2020, 2021). Percebendo-se o aumento dos crimes de feminicídio do início do isolamento social no Brasil em 26 de fevereiro de 2020 até o mês de julho de 2021.

Delitos de lesão corporal e ameaça, no ano de 2019, sendo considerado os meses de Janeiro até Julho foram contabilizados "12.056 lesão corporal e 21.952 crimes de ameaça" (SIP/PROCERGS,2019), mas nos anos seguintes e considerando os mesmos meses, ocorreu uma diminuição. Tendo no ano de 2020, "10.986 de lesão corporal e 19.670 crimes de ameaça" (SIP/PROCERGS,2020), e no ano de 2021, "9.794 de lesão corporal e 18.201 crimes de ameaça" (SIP/PROCERGS,2021), percebendo-se portanto, que crimes que por conta de uma cultura machista são levados com menor "gravidade", acabam não sendo possível o registro, pois o combate a covid-19 e a implementação do isolamento social, impossibilitou uma maior manifestação e repercussão de casos no Estado do RS.

Da mesma forma, crimes como de estupro no ano de 2019 e sendo considerado os meses de Janeiro a Julho, foram registrados "929 casos" (SIP/PROCERGS,2019), tendo o seu aumento nos anos seguintes, comtabilizando em nos mesmos meses de 2020, "1.112 casos" de estupro (SIP/PROCERGS,2020) e em 2021, "1.081 novos casos" (SIP/PROCERGS,2021). Demonstrando assim que crimes em que são levados com maior seriedade e repulsa social, tiveram seus registros aumentados, mas que se possa considerar a dificuldade de real identificação alarmante de registro, dificultada por conta do isolamento da pandemia e combate a Covid-19, não se isenta a importância e a continuidade de se combate e o monitoramento de vítimas e possíveis casos desse desfecho, não descartando juntamente a possibilidade de subnotificação nas situações de ameaça e lesão, em razão da convivência com os agressores durante o isolamento contra o coronavírus, reforçando a importância das denúncias. 


\section{METODOLOGIA}

A presente proposta de trabalho é de caráter de pesquisa científica, portanto, mostrase adequada a aplicação de um método de abordagem dedutivo, pois a partir da análise de quais direitos e garantias fundamentais das mulheres estão sendo observados na elaboração das políticas públicas de enfrentamento a agressões físicas, psicológicas, patrimoniais, sexuais contra mulheres em épocas de quarentena de prevenção a Covid-19 é que se saberá se as propostas de solução são suficientes para combater esse problema.

Os métodos monográficos e comparativos serão os utilizados no presente trabalho, tendo-se uma investigação de determinado assunto de utilização de conscientizar a sociedade, não somente em profundidade, mas em comparação a outros instrumentos jurídicos e de políticas públicas, visando analisar a posição doutrinária sobre o tema abordado e o conteúdo das normas que estipulam direitos e garantias e fixam políticas públicas de segurança para mulheres que sofrem injusta agressão em tempos atípicos de situação social a pandemia.

\section{RESULTADOS E DISCUSSÕES}

A problematização explanada ao decorrer dos capítulos, considerando assim que crimes de maior repulsa social, tiveram elevação em seus registros, a adversidades por conta do isolamento da pandemia e combate a Covid-19, não se isenta a importância e a continuidade de se combate e o monitoramento de vítimas e possíveis casos desse desfecho, não descartando juntamente a possibilidade de subnotificação nas situações, como exemplo de ameaça e lesão, em que não são consideradas de mesma proporção, em razão de maior receio pela convivência com os agressores durante $\mathrm{o}$ isolamento contra o coronavírus, com base nos dados obtidos e analisados, através da Secretaria de Segurança Pública do Estado do RS. 
Secretaria da Segurança Pública

Departamento de Planejamento e Integração

Observatório Estadual de Segurança Pública

MONITORAMENTO DOS INDICADORES DE VIOLÊNCIA CONTRA AS MULHERES NO RS

\begin{tabular}{|c|c|c|c|c|c|}
\hline MÊS & AMEAÇA & LESÃo CORPORAL & ESTUPRO $\left({ }^{*}\right)$ & FEMINICÍDIO CONSUMADO & FEMINICÍDIO TENTADO \\
\hline $\mathrm{jan} / 19$ & 3.765 & 2.116 & 184 & 3 & 44 \\
\hline $\mathrm{fev} / 19$ & 3.214 & 1.820 & 132 & 1 & 23 \\
\hline $\mathrm{mar} / 19$ & 3.457 & 1.949 & 126 & 11 & 25 \\
\hline $\mathrm{abr} / 19$ & 3.085 & 1.719 & 107 & 6 & 31 \\
\hline $\mathrm{mai} / 19$ & 2.893 & 1.499 & 104 & 11 & 23 \\
\hline $\mathrm{jun} / 19$ & 2.799 & 1.589 & 133 & 9 & 22 \\
\hline $\mathrm{jul} / 19$ & 2.739 & 1.364 & 143 & 14 & 37 \\
\hline
\end{tabular}

Secretaria da Segurança Pública

Departamento de Planejamento e Integração

Observatório Estadual de Segurança Pública

MONITORAMENTO DOS INDICADORES DE VIOLÊNCIA CONTRA AS MULHERES NO RS

\begin{tabular}{|c|c|c|c|c|c|}
\hline MÊS & AMEAÇA & LESÃo CORPORAL & $\begin{array}{c}\text { ESTUPRO } \\
\left({ }^{*}\right)\end{array}$ & $\begin{array}{c}\text { FEMINICÍDIO } \\
\text { CONSUMADO }\end{array}$ & $\begin{array}{c}\text { FEMINICÍDIO } \\
\text { TENTADO }\end{array}$ \\
\hline $\mathrm{jan} / 20$ & 3.797 & 2.220 & 202 & 10 & 22 \\
\hline $\mathrm{fev} / 20$ & 3.471 & 1.999 & 182 & 4 & 23 \\
\hline $\mathrm{mar} / 20$ & 2.894 & 1.813 & 167 & 13 & 20 \\
\hline $\mathrm{abr} / 20$ & 2.249 & 1.314 & 113 & 9 & 24 \\
\hline $\mathrm{mai} / 20$ & 2.412 & 1.224 & 147 & 7 & 31 \\
\hline $\mathrm{jun} / 20$ & 2.425 & 1.251 & 155 & 8 & 26 \\
\hline $\mathrm{jul} / 20$ & 2.422 & 1.165 & 146 & 2 & 21 \\
\hline
\end{tabular}

Secretaria da Segurança Pública

Departamento de Planejamento e Integração

Observatório Estadual de Segurança Pública

MONITORAMENTO DOS INDICADORES DE VIOLÊNCIA CONTRA AS MULHERES NO RS

\begin{tabular}{|c|c|c|c|c|c|}
\hline MÊS & AMEAÇA & LESÃO CORPORAL & $\begin{array}{c}\text { ESTUPRO } \\
\left({ }^{*}\right)\end{array}$ & $\begin{array}{c}\text { FEMINICÍDIO } \\
\text { CONSUMADO }\end{array}$ & $\begin{array}{c}\text { FEMINICÍDIO } \\
\text { TENTADO }\end{array}$ \\
\hline $\mathrm{jan} / 21$ & 3.289 & 1.902 & 204 & 11 & 30 \\
\hline $\mathrm{fev} / 21$ & 2.696 & 1.583 & 197 & 6 & 22 \\
\hline $\mathrm{mar} / 21$ & 2.677 & 1.467 & 163 & 3 & 31 \\
\hline $\mathrm{abr} / 21$ & 2.582 & 1.386 & 151 & 14 & 15 \\
\hline $\mathrm{mai} / 21$ & 2.372 & 1.116 & 128 & 8 & 9 \\
\hline $\mathrm{jun} / 21$ & 2.178 & 1.035 & 121 & 7 & 18 \\
\hline $\mathrm{jul} / 21$ & 2.407 & 1.305 & 117 & 9 & 19 \\
\hline
\end{tabular}




\section{CONCLUSÃO}

O presente tema possui elevada relevância no cenário atual, tornando justificável seu desenvolvimento a fim de trazer à compreensão da realidade e os problemas enfrentados por diversas mulheres gaúchas, bem como a avaliação da eficiência do mecanismo coercitivo do Estado frente ao panorama contemporâneo e a necessidade de execução de mais políticas públicas voltadas para a igualdade de gênero visando a redução dos casos de violência física, patrimonial, sexual, moral e psicológico, dentro do seu convívio social no Estado do Rio Grande do Sul. Conforme elucidado no decorrer do trabalho, tem-se uma percepção de que os dados trazidos não colidem com o clamor popular e de notícias midiáticas, pois é manifesto um volume retumbante de novos delitos.

Por fim, o trabalho acaba por não abordar o conflito existente entre os dados obtidos nos órgãos oficiais opositor aos problemas apresentados nas divergentes mídias informativas, estando os dados subestimados e não refletem a realidade, mas sim a dificuldade em registrar a denúncia durante o período de isolamento. A subnotificação ou a convivência em casa, não é um fator de estímulo à violência, mas sim a falta de políticas públicas mais efetivas com a implementação dos procedimentos contra crimes de violência doméstica e familiar contra a mulher ou em razão do gênero, necessitando que sejam mais eficazes e garantidores as condições para as vítimas e resguardando as mulheres de quaisquer danos, trazendo ainda mais severidade na responsabilização dos agressores.

\section{AGRADECIMENTOS}

Agradecemos à Universidade, por proporcionar o espaço para criação do presente trabalho. Agradecemos à orientadora Francielle, pelo carinho e pelo impacto em nossa formação. Agradecemos, sobretudo, às nossas famílias, em especial, Roselaine Barros, Volmar Rodrigues e Max Fernandes, Luciana Fernandes, nossos pais, por todo o apoio prestado. 


\section{REFERÊNCIAS}

BRASIL. Tribunal Superior Eleitoral, Título. Brasília, DF, 2014.

BOURDIEU, P. A dominação masculina. Rio de Janeiro: Bertrand Brasil, 1999.

COLLING, Ana. A Construção Histórica do Feminino e do Masculino. In: STREY, M.N.; CABEDA, S. T. L.; PREHN, D. R. (orgs.). Gênero e Cultura: questões contemporâneas. Porto Alegre: EDIPUCRS, 2004.

COLLINS, P. H. O que é um nome? Mulherismo, Feminismo Negro e além disso Disponível em: <http://www.scielo.br/scielo.php?pid=S010483332017000300510\&script=sci arttext>. Acesso em: 10 de abril de 2020.

PASINATO, W. Acesso à justiça e violência contra a mulher em Belo Horizonte. São Paulo: AnnaBlume, 2012.

Planalto LEI № 11.340, DE 7 DE AGOSTO DE 2006 Disponível em: http://www.planalto.gov.br/ccivil 03/ ato2004-2006/2006/lei//11340.htm Acesso em: 10 de abril de 2020.

Planalto LEI № 13.104, DE 9 DE MARÇO DE 2015. Disponível em: http://www.planalto.gov.br/ccivil 03/ ato2015-2018/2015/lei//13104.htm Acesso em: 10 de abril de 2020.

PEDRO, C. B; GUEDES, O. S. As conquistas do movimento feminista como expressão do protagonismo social das mulheres. Disponível:

$<$ http://www.mulheresprogressistas.org/AudioVideo/As\%20conquistas $\% 20$ do $\% 20 \mathrm{mo}$ vimento\%20feminista.pdf >. Acesso em: 10 de abril de 2020.

PINTO, C. R. J. Feminismo, história e poder. Disponível em:

$<$ http://www.scielo.br/scielo.php?pid=S0104-

44782010000200003\&script=sci arttext>. Acesso em: 10 de abril de 2020

POLÍTICA NACIONAL DE ENFRENTAMENTO À VIOLÊNCIA CONTRA AS

MULHERES. Secretaria Nacional de Enfrentamento à Violência contra as Mulheres.

Secretarias de políticas para as Mulheres - Presidência da República. Brasília, 2011.

Disponível em: https://www12.senado.leg.br/institucional/omv/entenda-

aviolencia/pdfs/politica-nacional-de-enfrentamento-a-violencia-contra-as-mulheres.

Acesso em: 16 de setembro de 2021.

SSP. Índice de violência contra a mulher. Disponível em:

https://www.ssp.rs.gov.br/indicadores-da-violencia-contra-a-mulher. Acesso em: 13 de maio de 2020.

TERRA, Rosane B. M. da Rocha B.; AQUINO, Quelen Brondani. A Justiça como Equidade: atributo necessário para a promoção dos direitos e garantias 
EDUCAÇÃO, SAÚDE

ETECNOLLGIA

26 A 28 DE OUTUBRO DE 2021

\section{QUFN}

fundamentais da mulher. In: DA COSTA, M. M. M.; RODRIGUES, H. T. (orgs.).

Direito \& Políticas Públicas VII. Curitiba: Multideia, 2012

WORLD HEALTH ORGANIZATION - WHO. Violence against women: a priority health issue. World Health Organization: Geneva, 1997. 